\title{
NATURAL HYBRIDS OF SUBSPECIES OF HIPPODAMIA QUINQUESIGNATA (COCCINELLIDAE) '
}

\author{
A. Franklin Shull \\ Unizersity of Michigan, Ann Arbor, Michigan
}

Received November 22, 1947

So much of the study of evolution is now being done in the laboratory that it behooves all who observe comparable phenomena in nature to put them on record. Whether the phenomena observed out of doors are actually examples of an evolutionary process must usually be decided by inference, at least in large part. and the one here recorded is no exception to this rule.

\section{The Original Observation}

What was at first hoped would prove to be a species cross was observed in a newly collected hibernating mass of lady beetles sent by Professor H. B. Yocom. They were collected on Spencer Butte, five miles south of Eugene, Oregon, at an elevation of 2200 feet, on April 6, 1942. Such masses tend to be composed of a single species. Of over 23,000 beetles in this mass, nearly all were Hippodamia sinuata spuria, whose pattern of heavy black spots (fig. 2, $C$ ) rests on a background of ochraceous buff (Ridgway). This species has a spotless phase, with which the typical spotted beetles cross freely (Shull, 1943). Among these black-and-buff beetles were somewhat over a hundred having a red ground color, mostly with few spots or none (fig. $2, A$ ). Nearly all of these, as identified by Dr. E. A. Chapin, to whom I wish to express my thanks, were Hippodamia quinquesignata ambigua. The form ambigua was formerly regarded as a distinct species, but is listed as a subspecies of quin-

1 Contributions from the Department of Zoology, University of Michigan. Aided by a grant from the Faculty Research Fund and a gift from Mrs. S. Ralph Lazrus. quesignata in Chapin's recent review (Chapin, 1946).

In the hibernating mass a spotless female ambigua was found copulating with a male sinuata spuria. The pair was removed, and continued copulating for more than an hour after its isolation. It was recognized that the female might have mated earlier with one of her own kind, even before entering the hibernating mass in the fall; but when some of the descendants of the female were distinctly spotted, it was first believed that the male sinuata spuria had shared in producing them.

Two circumstances, however, made it necessary to reject the spuria male as the source of spotting. First, none of the subsequent generations appeared to show any influence of the ochraceous buff ground color. All the descendants of the female in question had red ground color; and while there were variations in this color, none of them suggested a buff contribution. Exclusively red descendants could, it is true, be explained by assuming that ground color is in some sense a strictly maternal character. An attempt was made to test this possibility by mating female spuria with male ambigua, but all such attempts failed. This failure does not prove too much, since attempts to cross species in the lady beetles seldom succeed; and besides, a number of attempts to repeat the cross in the same direction (ambigua female $\times$ spuria male) likewise failed. When these attempts were made the beetles had already been inbred several generations, and everyone who raises the coccinellids seems to find the same rapid decline of vigor with in- 
breeding (Shull, 1944). Consequently, the failure to effect the species cross was then regarded as possibly no more than a failure of any cross, even within one of the species.

A more conclusive reason for rejecting any spuria contribution was the fact that all male descendants of the ambigna female had ambigua male genitalia. No one will know what kind of genitalia a hybrid of these species should have until the cross is made; but there should have been some kind of segregation in later generations, and there was none. A cross between Hippodamia convergens and $H$. quinquesignata (Shull, 1946a) resulted in intermediate genitalia in the hybrids. and subsequent segregation suggesting perhaps a three-gene differential between them. The absence of any sign of the sinuata spuria type of genitalia in the descendant males made it definitely necessary to conclude that the observed interspecific mating had not produced hybrid offspring.

What, then, was the source of the spotting of some of the descendants of the spotless ambigua female? The facts from which the answer to this question must be drawn by inference are presented in the following pages.

\section{The Prigree of Spotting}

From her own progeny the copulating ambigua female must be regarded as herself heterozygous for spotted, and it must be concluded that she had mated with a similarly heterozygous spotless male. The reasons for these assumptions are more precisely stated below. She is listed, therefore, as one member of a pair of spotless $\times$ spotless. Two other matings of the red beetles, guests in the hibernating mass of sinuta spuria, were made, both of them spotless $\times$ spotless. It is assumed, though not proven, that the males used were the fathers of the offspring obtained. These three females gave rise to the lines of descent, partly intermingled, shown in Figure 1. The female found copulating in the hibernat- ing mass gave rise to the progeny numbered 155 ; the male parent is unknown but is inferred to have been spotless, heterozygous for spotted. In the other two pairs, leading to progenies 157 and 151 , respectively, the male is known unless the females had mated before isolation.

In this chart, below the experiment number, are given the numbers of spotless and spotted individuals, the spotless (dominant) being shown first. Above the experiment number, the light sloping lines lead to the source or sources of the parents. It seems unnecessary, in this study, to distinguish the sexes of the parents, but whether they were spotted or spotless is indicated by the groups to which the light lines lead. Beside these lines are the genotypes assigned, sometimes with doubt, to the parents. $S$ is the gene for spotless, $s$ for spotted. In Experiment 166, which was first intended merely as a stock, two males were used, and two genotypes are given on the chance that one of the males might have been homozygous. If the female had mated with both a homozygote and a heterozygote, the small number of spotted offspring (distinctly less than one-fourth) might be explained.

\section{Criterion of Spotted and Srotless}

As is well known, "spotless" Hippodamia may, and often does, have spots. The only criterion yet established for distinguishing the amount of spotting proper to the spotted pattern from that possible in "spotless" beetles is the one determined (Shull, 1944, 1946b) in experiments with Michigan beetles of the species Hippodamia convergens. There is no direct evidence that the same standard can be applied even to other populations of $H$. convergens, since the validity of it would be affected by the number of modifying genes (judged to be three or four pairs in the Michigan population). Certainly there could be no assurance that this standard would apply to other species. Nevertheless, when this criterion was applied to the experiments with the 


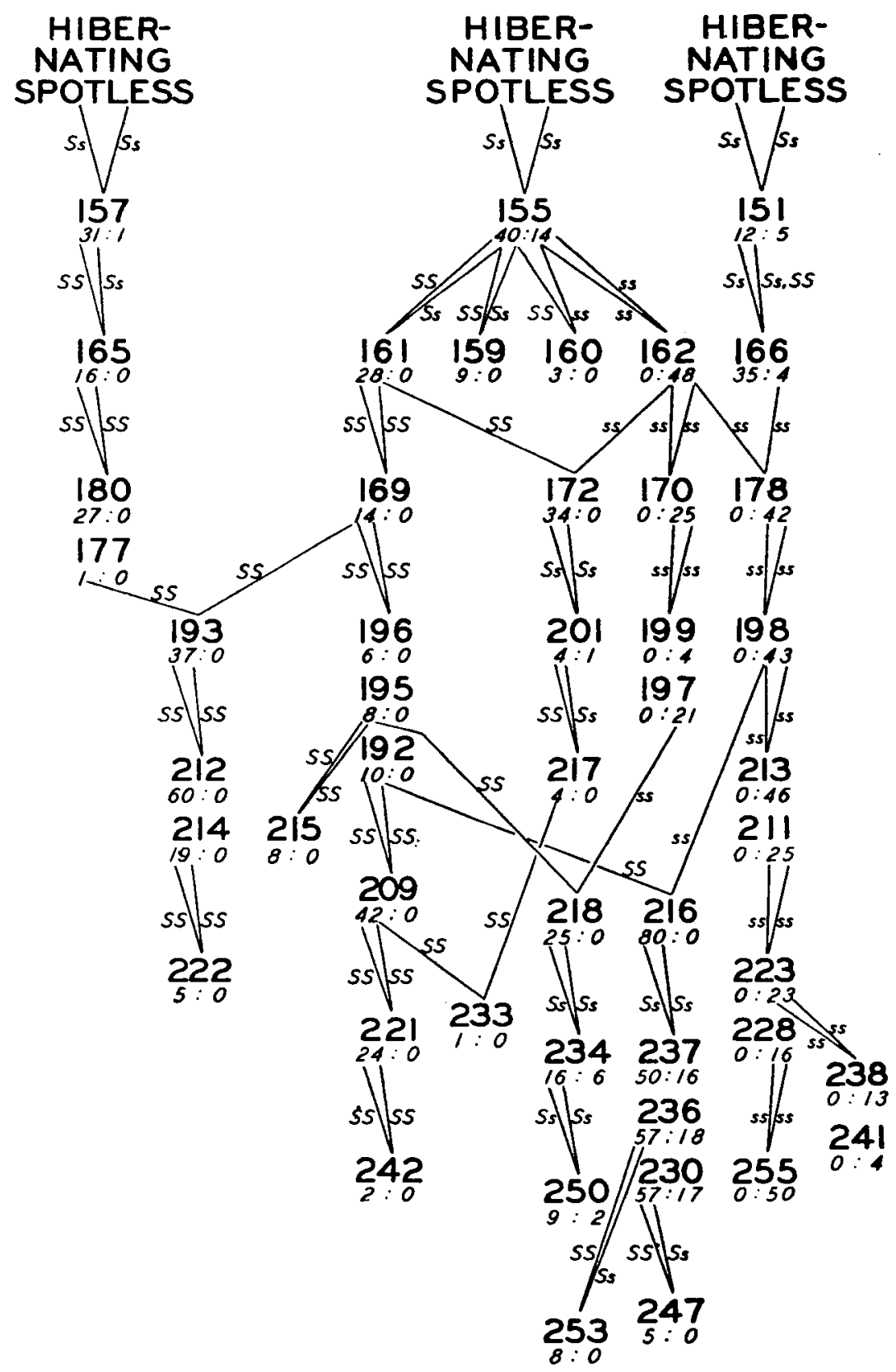

FIG. 1. Course of the experiments. Under the experiment numbers are the ratios of spotless to spotted beetles, spotless being given first. Over the experiment numbers the sloping lines indicate the source of the parents with the genotypes of the parents beside these lines. 
Oregon beetles of this paper, in matings which were known to be between two heterozygous spotless individuals, reasonably close approximations of the $3: 1$ ratio were obtained. In the absence of any other pertinent data, therefore, the Michigan standard has been used.

Any such standard is strictly valid only in a statistical sense, which is sufficient where ratios of spotless and spotted individuals are wanted. Almost certainly it would result in some mistakes concerning individuals. The dividing line between spotless and spotted was a total size rating of the three posterior spots of 7.75 in a possible maximum of 12 . Beetles having posterior spots larger than 7.75 were called spotted, those with smaller posterior spots were considered spotless.

Some information concerning the amount of overlapping between the amount of spotting of spotless and spotted beetles of the Oregon population can be gleaned from the experiments here reported. On the right side of the chart in Figure 1 are several lines of descent whose individuals must be "spotted" regardless of the size of their posterior spots. The details of these patterns cannot be given here for the hundreds of beetles because of space limitations, but some of the least spotted may be recorded. In progeny 162 , which must be consiclered wholly spotted, the six spots of one beetle were rated 003130, another 001121 (see Shull, 1944, for the scheme of rating). The three posterior spots had a combined rating of only 4 , in a possible maximum which for this strain was 13 instead of 12 . In Experiment 170 , descended from 162 , the least spotted beetle was 303330 . In 197 and 199, descended from 170 , the least spotted individual was 412133 . In progeny 178 , likewise all spotted, the three least spotted were 212120,100220 , and 133130 . In 198 , inbred from 178 , the least spotted was 301332. In the seven experiments descended from 198, only three beetles were as lightly spotted as the minimum one in 198. From their paucity one might suspect their reduction of spots was caused by developmental accidents, not genes.

In each of these two lines of descent the minimum rating shows a tendency to increase, as if modifying genes responsible for the reduction were being accidentally bred out.

Among the spotless lines of descent, the one descended wholly from 161 included only four beetles as much spotted as 000200 . In progenies 177 and 180 the most spotted beetle (so far as the posterior spots were concerned) was rated 000100 ; but 165 , from which they were bred, included one rated 030312 .

These statements regarding the criterion of spotting are of importance chiefly in relation to one individual in progeny 157. The rating of spots in this beetle is 040433 , and it was regarded as spotted. Its three posterior spots have a combined size rating of 10 , which is above the adopted dividing line. It is the only nember of 157 which meets the requirement of the genetically spotted pattern: the ratio of spotless to spotted is accordingly recorded as $31: 1$, and the parents are assumed to be both $S s$. The ratio is. however, so far from $3: 1$ as to raise the question whether this beetle were not genotypically spotless. Of the known spotless beetles of these experiments, none has posterior spots as large as 10 ; later in this same line of descent, as inlicated above, was one with posterior spots totaling 6 . Nowhere else in all the experiments was any beetle, known to be spotless, more heavily spotted than that.

Balancing the poor approach to the $3: 1$ ratio in 157 against the wide discrepancy between the posterior spotting of one beetle and the criterion of spotlessness, one must presumably leave in doubt whether the beetle recorded as spotted in 157 really is such. 


\section{Number of Heterozygous Guest BeEtles}

The principal significance of the discussion just closed is its bearing on the frequency of heterozygosis among the spotless red beetles hibernating with $H$. sinuata spuria. Six of these beetles were bred. Certainly four of them, the parents of 151 and 155, were heterozygous. The parents of 157 were both heterozygous if one of their offspring was spotted. If all the offspring in 157 were spotless, either or both of the parents were presumably homozygous. It is rather unlikely that both were homozygous; for if the six beetles chosen for breeding consisted of four heterozygous and two homozygous, there is only a minor chance that the four heterozygotes would have been arranged in two pairs and the two homozygotes in one pair. From these considerations it is concluded that at least four, probably as many as five, and possibly all six - of the spotless beetles which were bred were heterozygous.

From this conclusion it seems probable that a very considerable majority of the guest beetles, perhaps all of them, were heterozygotes. The possible significance of this frequency of heterozygotes is indicated later.

\section{Postmedian Band}

One feature of the spotted pattern needs to be separately treated. This is the fusion, in some of the beetles, of spots 4 and 5 into an oblique postmedian band (fig. 2). This band had already been studied in crosses between Hippodamia quinquesignata and $H$. convergens (Shull, 1945). In those hybrids the crosses had not borne too closely upon the mode of inheritance of the band, but on the whole the results were in best conformity with the conclusion that fusion of the spots into a band is recessive to their separation as distinct spots.

That conclusion is more definitely supported by the results reported here. In progeny 155 , of the 14 spotted individuals (see fig. 1), 9 had spots 4 and 5 separate, 5 had them joined. The parents of 162 were chosen from among the 9 whose spots were separate; their offspring included (among the total of 48 spotted) seven with spots 4 and 5 definitely joined and an additional one in which these spots were loosely or doubtfully joined. From among the other 40 with separate spots were taken the parents of 170 , among whose 25 spotted offspring only two had the spots joined, and these only doubtfully. Separate-spotted offspring of 170 gave rise to progenies 197 and 199, whose 25 spotted offspring (plus 5 not appearing in the chart because, through a confusion of records, they could have belonged to either 197 or 199) consisted of 22 spotted and 8 (one doubtfully) banded.

The original pair producing progeny 151 also possessed the banding factor, for, though none of the five spotted members of that progeny was banded, one of
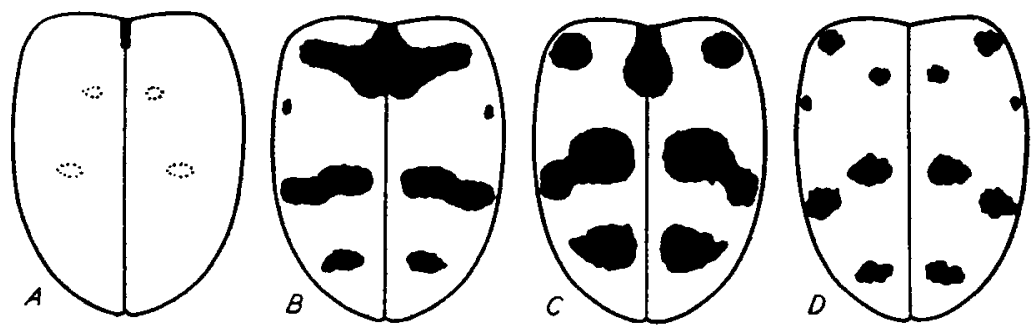

FIG. 2. Patterns of the elytra of four subspecies or species of Hippodamia. $A, H$. quinquesignata ambigua; $B, H$. q. quinquesignata; $C, H$. sinuata spuria; $D, H$. convergens. The dotted rings in $A$ represent occasional spots which might occupy any of the six positions of spots in $D$. 
the four in 166 (derived from 151) had spots 4 and 5 joined. Progeny 178, whose parents (one from 162, the other from 166) both had separate spots, included 23 separate-spotted, 11 banded, and 8 with the spots loosely or doubtfully joined. This ratio would probably better fit the assumption that one of the parents of 178 was homozygous for banding, but neither of them showed any sign of fusion.

Beyond this point in the pedigree is the first mating of two banded parents. The parents of 198 both had spots 4 and 5 distinctly joined. Of all this progeny and the seven others descended from it, each of them from two banded parents, every beetle except three was banded, and these three had spots 4 and 5 loosely joined.

From all the above data it seems necessary to attribute fusion of spots into a postmedian band to a recessive gene. In addition, however, there must be other genes modifying its expression to some extent. Both parts of this conclusion are in agreement with the earlier work on species hybrids (Shull, 1945).

\section{Source of Spotting}

In his review of the genus Hippodamia in North America, Chapin (1946) lists thirteen or fourteen subspecies, belonging to eleven species, having a distribution which would make them at least conceivable contributors to natural hybrids near Eugene, Oregon. It seems unnecessary to look outside the genus, since even species crosses, so far as now known, are infrequent. Among the subspecies available in that area, the probable source of the spotting in the hibernating guests reported here can be inferred only from such things as their relative abundance and the genetics of the pattern of the elytra and prothorax and of the shape of the male genitalia.

If the abundance of individuals is reflected in the number of collections which were available for Chapin's study, the ones that stand out as probable contributors to a cross are Hippodamia quinque- signata quinquesignata, H. q. ambigua, $H$. convergens, and $H$. sinuata spuria. The guests in the mixed hibernating mass were judged to be of the second of these subspecies, their hosts were of the lastnamed kind.

The convergent white marks on the prothorax, which all the guest hibernators and all their descendants had, could have come from all four of the abundant subspecies named above, and from three others -H. moesta moesta, $H$. caseyi, and $H$. sinuata sinuata. Nothing is known of the mode of inheritance of this pronotal pattern, but whether it is simple or complex there would presumably be some indication of segregation in the later hybrid generations unless the original pair of parents were alike with respect to it. Accordingly it is assumed that the unknown parents of the guest hibernators must both have had the convergent white marks.

The six spots on each elytron could probably be furnished by most of the species which are geographically so placed as to be considered. So many of the Hippodamia species which characteristically have bands occasionally have these bands broken up into spots that it seems likely that the spots form a common, genetically basic pattern (fig. 2). Of the geographically accessible types, according to Chapin's studies, the ones showing most definitely the six full spots on each elytron are $H$. tredecimpunctata tibialis and $H$. convergens, though $H$. quinquesignata quinquesignata sometimes has separate spots rather than the anterior and postmedian bands.

The fusion of spots 4 and 5 into a postmedian band, shown in the entire line descended from Exp. 178 and in portions of other progenies, must have been represented in the original parents. The guest hibernators were heterozygous for it, just as they were heterozygous for the general spotting. Marked fusion of these spots, without other bands, occurs in $H$. sinuata spuria, and sometimes in $H . q$. quinquesignata and $H$. caseyi, though the 

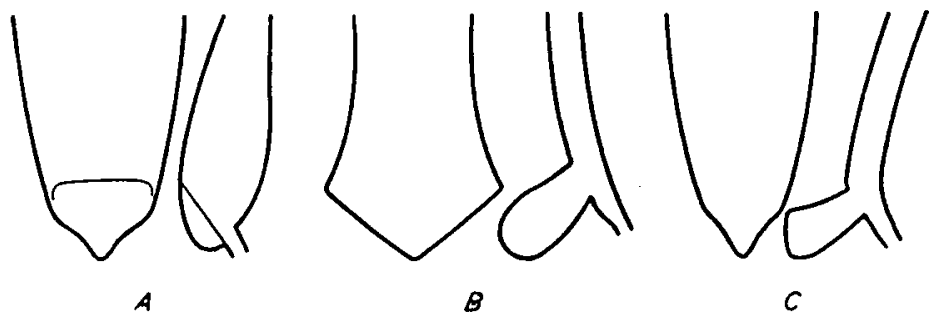

FIG. 3. Male genitalia of Hippodamia species, aedeagus at left in each species, distal end of sipho with flaps at right. $A, H$. quinquesignata; $B, H$. sinuata; $C, H$. convergens. Subspecies do not differ from the typical forms in these structures.

shape of this band in the hybrids here reported was similar only to that of quinquesignata. The other forms available in Oregon do not ordinarily have a band of this shape, nor this band without other bands.

The male genitalia of the hybrids appear to exclude all of the accessible species except $H$. quinquesignata as the source of spotting. The inheritance of coccinellid genitalia is known only for the cross of $H$. quinquesignata with $H$. convergens (Shull, 1946a), as stated earlier. In this cross, the specific difference in the male apparatus could rest on as few as three pairs of genes, without dominance and cumulative in their effect as between pairs. This distinction would account for the intermediate nature of the first-generation hybrids and the rapid approach toward the two parent types on repeated backcrossing. Intermediacy of the $\mathrm{F}_{1}$ of $H$. parenthesis and $H$. lunatomaculata was reported by Timberlake (1919), but no further generations were reared.

On the basis of these known facts one would expect the hybrids reported here to show a similar intermediacy in $F_{1}$ with segregation in later generations, but there was none. The male genitalia of all the hybrids, in all generations, were like those of $H$. quinquesignata-that is, like the males of the species to which the known female progenitors of these hybrid lines were assigned. All the genitalia have the sloping transverse keel or carina across the aedeagus; all have the heavy sipho, and low siphonic flaps shaped in outline like a low skew probability curve (fig. 3, A). The genitalia of no other species are nearly enough like these to constitute a likely source. Both of the hybridizing types must have carried genes for this form of genitalia.

From the evidence presented in this section it seems necessary to conclude that the guest hibernators were hybrid offspring of a spotted and a spotless $H$. quinquesignata, presumably $H$. q. quinquesignata and $H$. q. ambigua. One of these parents must have carried the gene for the fusion of spots 4 and 5 into a postmedian band. If either of them carried the gene for fusion of spots 1 and 2 into an anterior band, it could hardly have been homozygous for such gene, since none of the descendants showed any indications of this band.

\section{SOLRCE OF TIF: BANDING}

Most specialists would doubtless conclude that the gene for fusion of spots 4 and 5 entered with $H$. q. quinquesignata, which typically has such a band. One cannot rule out, however, the possibility that ambigua also has such a gene. Were a quinquesignata to acquire the spotless gene, which several species of Hippodamia possess in some individuals, and which can be transferred from $H$. convergens to $H$. quinquesignata without any apparent modification of its inhibiting effect on pattern .(Shull. 1945), it is likely that stuch an individual would be identified as ambigua. What genes for spot- 
ting the natural populations of ambigua possess cannot be told, of course, until genetic work, involving a fortunate mutation in that subspecies or a known cross with one of the spotted subspecies, has been done. Geographic separation of a quinquesignata population homozygous for the spotless gene could easily lead to the recognition of a spotless subspecies ambigua.

\section{Why H. Quinguesignata Guests of H. Sinuata?}

An important question, not yet answerable, is why the hundred or more individuals of $H$. quinquesignata ambigua were guests of the thousands of $H$. sinuata spuria. The mere fact of aggregation in winter, when hundreds of places for hibernation are available to single specimens, indicates presumably some attractive quality and a sense that responds to it. The additional fact that such masses are made up, in general, of a single species suggests that the quality and the capacity to sense it are specific in their nature.

When a main mass of one species is accompanied by a few individuals of another species, is that just an accidental result? Especially, is it accidental when the guests are found to be hybrids?

The idea that the hybrids discussed in this paper might have inherited a dominant sense from the species to which they were attracted in hibernation was one reason for supposing that one of their parents was $H$. sinuata spuria. As clearly shown, however, neither the pattern, nor the ground color, nor the genitalia of the descendants permit the assumption that the hybrid guests were offspring of a cross involving $H$. sinuata.

An alternative possibility is that certain species of Hippodamia, but not all of them, possess the mechanism of attraction, perhaps in different degrees. If $H$. q. quinquesignata should be sometimes found hibernating with sintata, while pure $H . q$. ambigua never is, this distinction might be traceable to an at- traction pair partly common. to quinquesignata and sinuata but not present in ambigua at all. Such a distinction would account for guest hibernation of the subspecific hybrids here described; it would also help to account for the observed isolation of ambigua from typical quinquesignata, which mere possession of the spotless gene could hardly explain.

\section{SUMMARY}

Some spotless red beetles assigned to the subspecies Hippodamia quinquesignata ambigua, and found hibernating with $H$. sinuata spuria, were shown by breeding experiments to be heterozygous for a spotted pattern. The spotting could not have come from spuria, their host, because the genitalia of the males among the hybrids were exclusively of the quinquesignata type, and because there was no recovery of the buff ground color of spuria in any of the descendants of the ambigua hybrids.

Most if not all of the guest hibernators must have been thus heterozygous, suggesting that their heterozygosis might be the reason for hibernating with sinuata spuria. Some dominant feature (perhaps an odor) of the mechanism which draws members of one species together in hibernation could be responsible for similar attraction in hybrids. However, since sinuata could not be one parent of the hybrids, other species must possess a similar attractive quality if this be the explanation of guest hibernation. Such a quality or the lack of it would be a more plausible reason for isolation of ambigua from quinquesignata than would the spotless gene which is their visible distinction.

It is concluded, partly from the pattern, that $H$. quinquesignata quinquesignata and $H$. q. ambigua were probably the parents of the hybrids. The experiments furnish confirmation of an earlier doubtful conclusion that the fusion of two spots into a postmedian band is caused by a single recessive gene. The hybrids must have been heterozygous for this gene. $H . q$. quinquesignata typically has 
the fusion gene; hence ambigua most probably lacks it.

\section{Literature Cited}

Chapin, E. A. 1946. Review of the New World species of Hippodamia Dejean (Coleoptera : Coccinellidae). Smithsonian Miscellaneous Collections, 106 (11) : 1-39, pls. 1-22.

Sнull, A. F. 1943. Inheritance in lady beetles. I. The spotless and spotted elytra of Hippodamia sinuata. Jour. Hered., 34: 329337.

- 1944. Inheritance in lady beetles. II. The spotless pattern and its modifiers in Hippodamia convergens and their frequency in several populations. Jour. Hered., 35 : 329-339.

- 1945. Inheritance in lady beetles. III. Crosses between variants of Hippodamia quinquesignata and between this species and H. convergens. Jour. Hered., 36: 149-160. 1946a. Inheritance in lady beetles. IV. The form of the chitinous male genitalia in crosses of the species Hippodamia quinquesignata and $H$. convergens. Genetics, 31: 291-303.

- 1946b. The standards by which the spotless phase of Hippodamia convergens is judged. Ann. Ent. Soc. Amer., 39: 190-192.

Timberlake, P. H. 1919. Notes on the North American species of Hippodamia (Coleoptera). Jour. N. Y. Ent. Soc., 27 : 162-174. 